\title{
Impact of lesson study on mathematics anxiety and mathematics achievement of Malaysian foundation programme students
}

\author{
Hosseinali Gholami ${ }^{1}$, Ahmad Fauzi Mohd Ayub², Aida Suraya Md Yunus ${ }^{3}$, Nurzatulshima \\ Kamarudin 4 \\ 1,2,3,4 Institute for Mathematical Research, Universiti Putra Malaysia, Malaysia \\ ${ }^{2,3,4}$ Faculty of Educational Studies, Universiti Putra Malaysia, Malaysia
}

\begin{tabular}{l} 
Article Info \\
\hline Article history: \\
Received Jan 27, 2020 \\
Revised Jun 18, 2021 \\
Accepted Jul 17, 2021 \\
\hline
\end{tabular}

Keywords:

Lesson study

Mathematics anxiety

Mathematics lecturer

Research lesson

\begin{abstract}
Based on many researches, there is negative relationship between mathematics anxiety and achievement. However, there is no study about mathematics anxiety and achievement in Malaysian foundation centers. This research studied the impact of Lesson Study (LS) on mathematics anxiety and achievement of students in a Malaysian university. A total of eight lecturers were involved in planning the LS which was experimented on 44 students as experimental group, while 42 others were in the control group. In the experimental group, students solved problems individually and in teams in a student-centered approach. For the control group, students were taught using the conventional method. Mathematics anxiety was measured using the Mathematics Anxiety Scale-Revised (MAS-R). A mathematics test was used to measure the students' ability in problem solving. The data was analyzed using t-test, ANOVA and MANOVA. The results showed that there is a significant difference between the means of the experimental and control groups in mathematics anxiety and achievement scores. However, there is no statistically significant interaction between the effects of educational method and gender on both mathematics anxiety and achievement. LS was found to be a suitable method to increasing the student's ability in problem solving and reducing their anxiety.
\end{abstract}

This is an open access article under the CC BY-SA license.

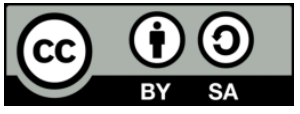

\section{Corresponding Author:}

Ahmad Fauzi Mohd Ayub

Institute for Mathematical Research and Faculty of Educational Studies

Universiti Putra Malaysia

43400 Serdang, Selangor, Malaysia

Email: afmy@upm.edu.my

\section{INTRODUCTION}

In Malaysia, students have to attend a pre-university programme such as matriculation or foundation programmes before they can be admitted for their bachelor programme. Foundation programme requires at least a B grade in mathematics, physics, chemistry and biology in the high school examination. In the foundation programme, students are engaged with more advanced topics and complex mathematics problems as compared to secondary level. As highlighted by Tambychik and Meerah some students in foundation and upper secondary levels have difficulties about problem solving because of their beliefs, skills and abilities [1]. Therefore, some may encounter emotional and mental problems such as mathematics anxiety that is related to mathematical thinking and problem solving [2].

Mathematics achievement has been found to be strongly related to problem solving skills among students [3], [4]. In the learning of mathematics, some students just memorize the materials such as theorems, formulas, methods and shortcuts, thus they may have superficial understanding about the mathematics 
principles and concepts [4], [5]. These students face some difficulties when the educators make slight changes in the exercises and they are not able to solve the given problems. This resulted in the concern and anxiety about mathematics learning and problem solving. It also influence their beliefs and ideas that "mathematics is a hard subject and difficult to learn" [6]. Many educational researchers work on finding new ways of teaching, linking concept and real-life applications and motivating the students to take more interest in the subject to overcome mathematics phobia and anxiety [7]. Hattie explained that student's mathematics performance is not related to students' abilities and characteristics, but other factors such as teaching methods have significant role in student's performance [8]. This is supported by Patrick, Mantzicopoulos, Samarapungavan, and French who believe that the main reason of mathematics anxiety is related to the teaching method and the use of traditional method which do not encourage students to learn mathematics through logical arguments [9]. She added that educators cannot reduce the mathematics anxiety if they do not use the problem solving method in their classes.

From the early 21 th century, there have been a lot of researches about Lesson Study (LS) in different countries in the world and some countries started this model in their education systems as part of teachers' professional development. For example, LS was introduced among teachers in Indonesia since 2005 [10] and in Malaysia since 2011 [11]. Harsono found that LS is a strong method in improving the content knowledge $(\mathrm{CK})$ and pedagogical content knowledge (PCK) of mathematics educators which is conducted through collaborative effort [10].

Shulman defined mathematics teacher's CK as teacher's knowledge of the mathematics subject matter that they teach [12]. Teachers' $\mathrm{CK}$ is related to the mathematical quality of their instruction and teaching styles [13]-[15]. Similarly, Norton explained that knowledge of mathematics content to be taught is a key component in influencing the quality of teaching, furthermore, teachers who know more mathematics are likely to teach better [16]. Shulman defined PCK as "the blending of content and pedagogy into an understanding of how particular topics, problems, or issues are organized, represented, and adapted to the diverse interests and abilities of learners, and presented for instruction" [14, p. 8]. In relation to this, Yusof and Zakaria explained that mathematics teachers focus mostly on CK and they are least likely to integrate CK with PCK, while in fact, mathematics teachers need to have high level of CK and PCK in order to improve their students in mathematics learning through the use of suitable teaching methods [17]. Hence, this will also reduce the mathematics anxiety among students.

The purpose of this study was to investigate the impact of the implementation of LS on mathematics anxiety and mathematics achievement of students who are pursuing the foundation programme. Their mathematics teachers (referred to as lecturers) collaboratively planned to identify suitable problems, practical problems and share their knowledge and experiences about different topics in order to motivate and encourage students in mathematics learning by using interesting materials and suitable methods through student-centered approach. When students do the activities in the class, they are introduced to many new methods of solving a problem, hence expanding their ideas and skills in mathematics problem solving. This can also help students to have better confidence in their abilities and may result in decrease of their anxiety in mathematics learning.

Xenofontos and Andrews defined mathematics task as a problem if students are engaged with the task for the first time and the question is a challenge for them, otherwise the task is merely an exercise [18]. Over time, a problem after being discussed in the class, may just be regarded as an exercise by the students. Further a problem that relates to students' everyday life or other subjects is referred to as a practical problem.

Nowadays, the teaching and learning of mathematics strongly relate to problem solving skills. Therefore, educators need to have high level of problem solving skills, and both CK and PCK. Otherwise, educators cannot develop the students' abilities in mathematics learning. In traditional way of teaching, educators emphases on exercises, hence are resulting in students just memorizing the materials superficially. Thus, they are not able to develop the ability to solve problems. Some students believe that mathematics is a difficult subject and they cannot learn it. This is the start of psychological problems among students about their mathematics learning which may end up with mathematics anxiety. Thus, it is of utmost importance that the lecturers identify the most suitable teaching method to improve students' learning through problem solving and higher order thinking. There are a lot of problem solving models that provide guide to students through the four phases in solving a problem [19], which are understanding problem, planning, performing the plan and confirming of the answer. Lecturers can introduce and guide students to use this step by step problem solving model to improve in mathematics learning.

Girls are seen as successful in mathematics learning due to their hard work [20], [21] while boys' success is attributed to their talent [22]. According to Trends of International Mathematics and Science Studies report [23], 8th grade female students in Malaysia had better performance in mathematics as compared to the males in all TIMSS assessments. Although male and female students show equal competencies in mathematics learning [24] gender gaps in terms of mathematics attitudes, perceptions, and 
interests remain prominent. Specifically, girls are more likely than boys to report negative feelings toward mathematics [25]. This study is under the premise that LS can improve all students in mathematics learning irrespective of their gender [9].

Two Japanese words "Jugyo" and "Kenkyu" means lesson and study respectively thus the term "Jugyo Kenkyu" was translated to LS by Yoshida in 1999 [26] in his doctoral dissertation [27]. However, Abiko pointed out that this educational method was introduced a long time ago in the 1950's in Japan as teachers professional development model [28]. Since 1999, a lot of researchers studied the LS in their education systems. In 2011, LS was introduced formally in the Malaysian education system by the Ministry of Education through the Professional Learning Community (PLC) [11]. As a result, many of the Malaysian states tried it out. One such example was the implementation of LS which was carried out in 42 secondary schools in the state of Sabah to improve the quality of teaching [29].

In learning situations, problems should be on such levels that every learner would be able to solve at least some of the problems to some extent, and this will encourage his/her motivation [30]. In the past two decades, mathematics researchers and educators had focused on mathematics learning through problem solving. The aim of LS, based on the cognitivist learning theory, is to enhance students' understanding of mathematical concepts and skills using problem solving method, thus the teacher is expected to facilitate mathematical discussion for students to achieve this goal [27], [31].

LS requires a group of mathematics educators to work collaboratively about a topic and spend a lot of time in planning a lesson, teaching or/and observing the lesson, reflecting and discussing on the taught lesson in order to improve student's achievement in mathematics learning through problem solving [29]. These collaboratively planned lessons are called research lessons [32] or study lessons [33].

Researchers have introduced several models of LS which was conducted in different number of phases, in this study, the Japanese LS model that was suggested by Fujii was used as a professional development of the lecturers [34]. Fujii's model of LS was introduced in 2014 and it involves five phases as:

a. Goal setting: In this phase, educators focus on long-term goals in order to improve students' learning, problem solving and achievement.

b. Lesson planning: Educators collaboratively design a research lesson with suitable mathematics materials to improve students' abilities in higher order thinking and problem solving skills.

c. Research lesson: After preparing the research lesson, one member of the LS group teaches the research lesson and other members observe and collect data in order to improve the research lesson.

d. Post-lesson Discussion: Through post-lesson discussion, educators consider students' learning and misunderstanding, unit design and disciplinary content to enrich the research lesson.

e. Reflection: Educators discuss new questions about the research lesson and they collaboratively plan to solve these problems in the next cycle of LS. Also in this phase, educators prepare a report about the research lesson.

By using LS approach, lecturers can improve the ability of students in problem solving and higher order thinking. As a result, mathematics performance of students will improve accordingly. In fact, by engaging with problem solving and practice, students not only learn the mathematics concepts meaningfully but they will also improve their self-confidence about learning mathematics. Therefore, based on the Deficit Theory, this will consequently reduce the mathematics anxiety among students.

It is clear that mathematics anxiety has affected the quality of teaching and learning directly or indirectly [35]. There are a lot of definitions for mathematics anxiety and in this study, it is defined as the "feeling of tension and anxiety that interfere with the manipulation of numbers and the solving of mathematical problems in a wide variety of ordinary life and academic situations" [36, p.551]. Mathematics anxiety could develop as a result of students' prior negative experiences in learning mathematics such as low marks, superficial learning about the concepts and low level of problem solving skills [37]. Therefore, educators should play an important role in reducing the level of mathematics anxiety among their students by providing positive and effective learning environment. The results of some studies on the mathematics anxiety in Malaysia illustrate that approximately a third of students in secondary schools suffer from high level of mathematics anxiety [35], [38].

There are some important factors that cause the mathematics anxiety among students such as limited time given to solve a problem, emphasis on correct answers, competition and the fear of looking or feeling "stupid" in front of others [39]. Also, some special instructional techniques in mathematics teaching such as directly following textbook examples, lecture method, and emphasizing only on one way to solve a problem are among the main causes of mathematics anxiety [39]. It seems that in the foundation level and upper secondary schools, memorizing the materials, strong relationship between different topics, teaching methods and students' weaknesses in problem solving are some important reasons that contribute to the increase in mathematics anxiety among students [6]. 
There is a significant relationship between low mathematics achievement and high level of mathematics anxiety among students in high schools [6], [38], [40]-[42] as well as among university students [43]. Furthermore, students with high level of mathematics anxiety are found to be engaged in negative thinking about their self-ability [38], [44]. This is an important challenge for educators, policy makers and administrators to find suitable methods in their educational systems in order to encourage students to learn mathematics deeply and reduce the level of mathematics anxiety.

Many studies have also shown that female students experience higher levels of mathematics anxiety as compared to male students [45]-[47] because female students are usually more shy as compared to male students and sensietive about the performance scores [38]. Although some researches do not support this theory and have revealed that there is no difference in levels of mathematics anxiety between gender [35], [38], [48].

There is a strong relationship between mathematics anxiety and math achievement [49]. Carey, et al. explained the relationship between mathematics anxiety and mathematics performance as Deficit Theory [50]. They suggested that students with poorer performance are more likely to increase their anxiety about mathematics. LS programme enhanced the lecturers' teaching performance by improving their CK and PCK. As a result, mathematics performance of students will improve accordingly. Based on the Deficit Theory, this will consequently reduce the mathematics anxiety among students. Therefore, the theoretical framework for this study is can be seen in Figure 1.

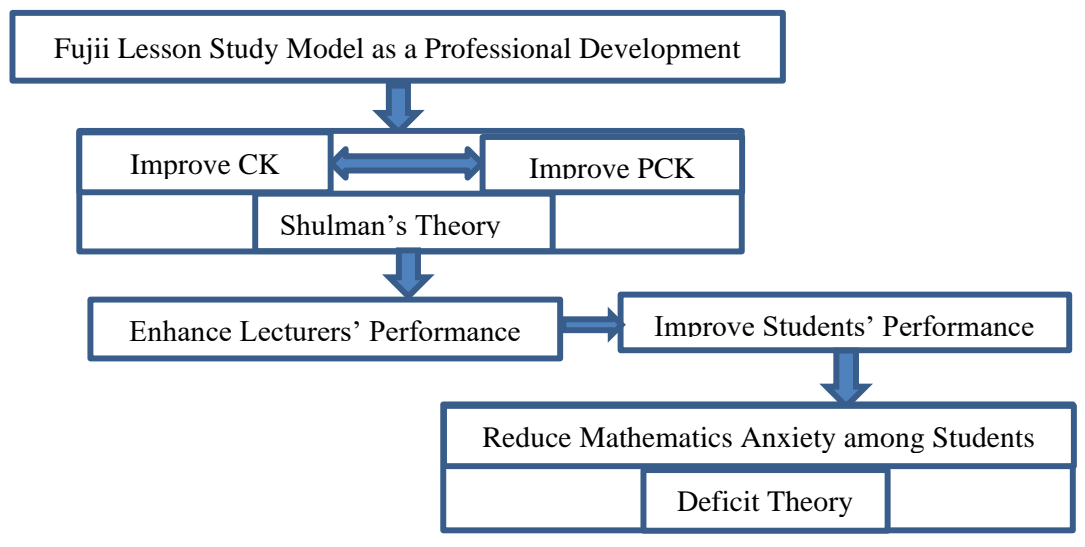

Figure 1. Theoretical framework for the study

\section{RESEARCH METHOD}

This quasi-experimental research was conducted in a Foundation Center of a public university in Malaysia. As stated in the problem statement, no studies on the impact of LS on achievement and mathematics anxiety had been conducted involving students beyond high school, as in this case, at the preuniversity or foundation level. Thus, students of this Foundation Center were chosen in the study on the impact of LS on mathematics anxiety and mathematics achievement.

The researcher had to opt for quasi-experimental research since it was impossible to divide students into two groups for the study because students have different time schedule for their mathematics courses and are taught by different lecturers. The LS group involves eight lecturers (seven mathematics lecturers and a physic lecturer) and a total of 86 students, comprising of 44 students in the experimental group (Lesson Study group) and 42 students in the control group. In this research, the researcher played several roles such as coordinator, discussion leader, and participant of the LS group. Before starting this study, permission was obtained from the director of the center, the lecturers and students.

The measurement tool used in this study to measure mathematics anxiety among students was the Mathematics Anxiety Scale-Revised (MAS-R). This test was originally developed by Betz [51] and was later improved by Bai in 2011 [52]. The researcher had sent an email to Bai and he agreed to give his permission to use this instrument. The MAS-R has 14 items of which six (43\%) are positive items $(1,3,5,10,12$ and 13) and eight (57\%) are negative items $(2,4,6,7,8,9,11$ and 14). Examples of items are "I worry about my ability to solve mathematics problems" (negative item) and "Mathematics is one of my favorite subjects" (positive item). It uses a 5-point Likert scale, ranging from 1 (strongly disagree) to 5 (strongly agree). So, the minimum and maximum scores for this instrument are 14 and 70 respectively. For positive items, the scoring was reversed (because this instrument measures the mathematics anxiety), thus a high score indicated the 
respondents are experiencing high mathematics anxiety. The positive correlations of all items with the total scale ( $\mathrm{r}=0.71$ ) suggest that all 14 items of MAS-R consistently measured the same construct.

Before the study was conducted, the anxiety instrument was pilot tested on 30 foundation students who were not subjects of this research. This was necessary to establish the suitability of the instrument. The Cronbach's coefficient alpha for the 14 items was 0.83 and the validity of this instrument was confirmed by some experts in educational psychology and mathematics education of a Malaysian university. Although all subjects are taught in English and all textbooks used in the Foundation Centre are in English, the instrument also includes the Bahasa Melayu (Malaysian language) translation so as to avoid ambiguity for students. Thus, back to back translation from English to Bahasa Melayu was done by two experts of English Language from one of the faculties from the same university. The final version was confirmed by two experts in mathematics education in order to ensure there was no problem in the translation.

Another measurement used in this study was the tests developed by the lecturers involved in the LS, as well as the researchers. It contains 12 open-ended problems, which was tested for its contextual validity and reliability and was proved by using Equivalent-forms Method. Six experts in mathematics and mathematics education from the same university confirmed the validity and suitability of these problems. The Pearson correlation significant for pre-test with 31 and post-test with 40 participants outside this study were 0.780 and 0.749 respectively. Meanwhile, these tests (included Bahasa Melayu the process of translation was the same MAS-R) were different because new concepts were taught in these five weeks. Also, post-test was conducted one month after finished the study again as follow-up test. An example of pre-test is "The graph of the function $f(x)=\frac{a x+3}{x-b}$ passes from two points $(-1,0)$ and $(1,-2)$. Find the values of $a$ and $b$ " and in posttest is "Let $m$ be a non-zero constant. Find the two $x$-values where the graphs of the functions $y=10^{6 m} x$ and $y=\frac{x^{2}}{10^{5 m}}$ intersect". Both the MAS-R and the mathematics tests were approved by experts in the Ethical Committee of the Research Management Center (RMC) as suitable instruments for the study.

The students' answers in the test were scored by two lecturers [19]. If student showed no understanding of the problem (illogical and incorrect answer) or no answer given, then the question is given a score 0 . If some steps are given in the solution that indicates that student understand the problem, the score given is 1 (first step of Polya's model). If student understand and design a method for solution but made some errors, the score is 2 (first and second steps of Polya's model) and finally, a completely correct answer is given a score of 3 (acquiring all steps of Polya's model). So, the minimum and maximum scores for the test were 0 and 36 respectively.

LS group members collaboratively planed discussed and designed five research lessons about the topic on function based on problem solving approach. The topics were chosen because these contents will be further applied in other mathematics courses at the university level. Therefore, during this study, mathematics lecturers improved their CK and PCK considerably because they discussed about different solutions for a given mathematics problem, application of the topic in everyday life, take into considerations students' misunderstandings about different subtopics and select the most suitable methods to teach the materials to students. The planning of LS in this study started with the researcher introducing on research lesson to the lecturers. They searched, studied and collected information related to it the content chosen. In the subsequent LS meetings, which total up to 20 hours, they already had appropriate information to discuss and share with colleagues. The lecturers emphasized on the problems, practical problems, fun examples and suitable instructional methods in order to improve students' abilities in mathematics through individual student activities and in teams. During another session, a lecturer was asked to voluntarily teach the research lesson while the other lecturers observed. At the end, the lecturers discussed about the strengths and the weaknesses of the research lesson and they collaboratively tried to improve the quality of the lesson. The role of the physic lecturer was to help the mathematics lecturers to apply suitable practical problems and suggest the applications of the mathematics topics in physics.

A mathematics lecturer, who is part of LS group was chosen randomly and his/her classes were randomly assigned as experimental and control groups. The LS approach was implemented for five weeks, which covered five topics on functions. In the experimental group, the student-centered teaching approach was applied and the lecturer gave some problems and practical problems that students did individually and in teams. It was meant to improve students' abilities, motivation and interest in mathematics learning. In the conduct of the research lessons, the lecturer walked around the class to provide guide, to assess and encourage students in their activities. In contrast, the control group was lecturer-centered and the same lecturer taught the exact same content but using conventional method where students are required to work individually with emphasis on mathematics exercises. The MAS-R and the mathematics achievement test were administered at the beginning and at the end of the study in order to compare the levels of mathematics anxiety and problem solving ability between the two groups. Data were analyzed using independent sample ttest, ANOVA test and MANOVA test. 


\section{RESULTS AND DISCUSSION}

The normality of mathematics achievement scores is shown in Table 1. Since the value of $p$ for all groups are greater than 0.05 , the scores are normally distributed. Table 2 shows the result of independent sample $t$-test for mathematics achievement test in the pre-test, the post-test and the follow-up test. There is no significant difference between means of the Lesson Study group and the control group in pre-test. But there is significant difference between means of the Lesson Study group and control group in the post-test. Also, there is significant difference between means of the Lesson Study group and control group in the follow-up test. Therefore, LS was suitable and enjoyable educational method to improve the students' abilities in problem solving and mathematics learning as compared to the conventional teaching method. The homogeneity of variances by gender is shown in Table 3 .

Table 1 . The normality of mathematics scores

\begin{tabular}{ccccccc}
\hline \multirow{2}{*}{ Group } & \multirow{2}{*}{ Test } & \multirow{2}{*}{ Skewness } & \multirow{2}{*}{ Kurtosis } & \multicolumn{3}{c}{ Kolmogorov-Smirnov } \\
& & & Statistic & df & Sig \\
\hline \multirow{3}{*}{ Lesson study } & Pre-test & 0.008 & -0.895 & 0.120 & 44 & 0.115 \\
& Post-test & -0.516 & 0.685 & 0.102 & 44 & 0.200 \\
& Follow-up & -0.198 & -0.892 & 0.119 & 44 & 0.135 \\
\multirow{3}{*}{ Control } & Pre-test & -0.224 & 0.714 & 0.100 & 42 & 0.200 \\
& Post-test & -0.196 & -0.342 & 0.107 & 42 & 0.200 \\
& Follow-up & 0.318 & 0.379 & 0.093 & 42 & 0.200 \\
\hline
\end{tabular}

Table 2. Comparing the mean of mathematics scores in post-test and follow-up test

\begin{tabular}{cccccccc}
\hline Test & Group & Number & Mean & Standard deviation & T & df & Sig \\
\hline Pre-test & Lesson study & 44 & 18.22 & 3.99 & -1.632 & 84 & 0.106 \\
& Control & 42 & 19.83 & 5.08 & & & \\
Post-test & Lesson study & 44 & 24.02 & 4.64 & 5.326 & 84 & 0.000 \\
& Control & 42 & 19.07 & 3.92 & & & \\
Follow-up & Lesson study & 44 & 23.52 & 3.75 & 5.117 & 84 & 0.000 \\
& Control & 42 & 19.28 & 3.92 & & & \\
\hline
\end{tabular}

Table 3. Levene's test for homogeneity of variances

\begin{tabular}{ccccc}
\hline Test & Levene statistics & df1 & df2 & Sig \\
\hline Pre-test & 4.522 & 3 & 82 & 0.060 \\
Post-test & 0.800 & 3 & 82 & 0.498 \\
Follow-up test & 1.260 & 3 & 82 & 0.294 \\
\hline
\end{tabular}

The results of two-way ANOVA test about the pre-test illustrates that there is no statistically significant interaction between the effects of educational method and gender on mathematics scores $F(1,82)=0.007, \mathrm{p}=0.936$. Two-way MANOVA test was conducted to show the differences among groups by gender in post-test and follow-up test. Box's test of equality of covariance matrices showed the assumption of equality of covariance was met because $\mathrm{p}=0.068, \mathrm{p}>0.05$. The result of multivariate tests represented that there is no statistically significant interaction effect between type of educational method and gender on the mathematics scores in post-test and follow-up test, $F(2,81)=0.769$, p=0.467; Wilks' $\Lambda=0.981$.

The normality of data for mathematics anxiety scores was considered using Kolmogorov-Smirnov test. According to Table 4, the $p$-values for all groups are greater than 0.05 , so the scores does not differ from normal distribution. Table 5 shows the results of the independent sample t-test of anxiety scores between the Lesson Study and control groups in the pre-test and post-test. The results showed that there was no significant mean difference in mathematics anxiety between the Lesson Study group and control group in the pre-test. However, there was a significant mean difference in mathematics anxiety between the Lesson Study group and control group in the post-test. In other words, LS was effective in reducing the mathematics anxiety among students as compared to conventional method. The homogeneity of variances by gender is shown in Table 6. Since the value of $p$ is greater than 0.05 , the assumption of homogeneity of variances among groups by gender was met.

Two-way MANOVA test was conducted to show the differences among groups by gender in pretest and post-test. Based on the Box's test of equality of covariance matrices, the assumption of equality of covariance was met because $\mathrm{p}=0.199, \mathrm{p}>0.05$. The result of the multivariate tests showed that there is no statistically significant interaction effect between type of educational method and gender on the mathematics anxiety scores in pre-test and post-test, $F(2,81)=1.347, \mathrm{p}=0.266$; Wilks' $\Lambda=0.986$. 


\begin{tabular}{ccccccc}
\multicolumn{2}{c}{ Table } & 4. Normality test for mathematics anxiety scores \\
\hline \multirow{2}{*}{ Group } & & \multirow{2}{*}{ Skewness } & \multirow{2}{*}{ Kurtosis } & \multicolumn{3}{c}{ Kolmogorov-Smirnov } \\
& & & & Statistic & df & Sig \\
\hline \multirow{2}{*}{ Lesson study } & Pre-test & 0.200 & 0.239 & 0.074 & 44 & 0.115 \\
& Post-test & -0.620 & 0.143 & 0.058 & 44 & 0.200 \\
Control & Pre-test & -0.197 & -0.170 & 0.111 & 42 & 0.200 \\
& Post-test & -0.010 & 0.666 & 0.109 & 42 & 0.200 \\
\hline
\end{tabular}

Table 5. Comparisons of the pre-test and post-test means of mathematics anxiety scores

\begin{tabular}{cccccccc}
\hline Test & Group & Number & Mean & Standard deviation & T & df & Sig \\
\hline Pre-test & Lesson study & 44 & 34.04 & 8.58 & -0.929 & 84 & 0.35 \\
& Control & 42 & 35.76 & 8.55 & & & \\
Post-test & Lesson study & 44 & 32.79 & 7.91 & -2.48 & 84 & 0.01 \\
& Control & 42 & 37.42 & 9.35 & & & \\
\hline
\end{tabular}

Table 6. Test of homogeneity of variances among groups by gender

\begin{tabular}{ccccc}
\hline Test & Levene statistic & df1 & df2 & Sig \\
\hline Pre-test & 0.372 & 3 & 82 & 0.773 \\
Post-test & 0.157 & 3 & 82 & 0.925 \\
\hline
\end{tabular}

This study has been conducted to study the impact of LS on mathematics anxiety and achievement among foundation level students in a Malaysian university. The results of this study showed there was an increase in the pre-test, post-test and follow-up test mean scores of mathematics achievement which were $18.22,24.02$, and 23.52 respectively for the experimental group. Whereas, there was no change in the pretest, post-test and follow-up test mean scores which were 19.83, 19.07, and 19.28 respectively in control group. LS was effective and found to be a suitable educational approach to help increase the students' abilities in problem solving. The results of this study also represented that the mean of mathematics anxiety scores was 34.04 for pre-test and 32.79 for post-test in the experimental group. However, there was an increase in the pre-test and post-test scores which were 35.76 and 37.43 respectively for the control group. The results illustrated that LS method reduced the mathematics anxiety among students but in control group it is the opposite.

Although problem solving is enjoyable for the majority of students and they can experience the beauty of mathematics, some students had concern about their abilities in problem solving because of their poor basic knowledge in mathematics. Many students believed that mathematics is a challenging subject. It could be a result of memorization of materials such as formulas, theorems and methods which was often the practice done at the school level. However, they may experience less difficulties if they learn the concepts meaningfully which can help improve their power to do problem solving considerably and to reduce the feeling that mathematics is difficult. For example, the students memorize many trigonometric formulas such as $\sin (\pi-\theta)=\sin \theta$ and $\tan (2 \pi-\theta)=-\tan \theta$ but if they learn the trigonometric circle conceptually, they can learn many trigonometric formulas easily. Students in this study engaged with many conceptual understanding and they had improved their abilities in problem solving, which may consequently improve their self-confidence in mathematics learning and hence, reduce their mathematics anxiety. The findings of this study support earlier findings [6], [41], [38].

In the LS group, students had the opportunity to be engaged with practical problems and this provided awareness that mathematics knowledge will be used in their career and everyday life. When students were engaged with mathematics concepts through problem solving, they were able to learn the mathematics conceptually and this helps them to have better view of mathematics learning. In general, the results of this study reported that the lecturers in LS programme improved the ability of students in problem solving thus they decreased the mathematics anxiety among students because students learned the mathematics conceptually and they didn't need to memorize many materials. Preparing suitable mathematics problems in LS approach not only engage students with logical learning process but also it is designed on a belief that every student is able to learn mathematics at a higher level. Therefore, learning the problem solving skills had improved positive attitude to mathematics among students and reduce their mathematics anxiety.

Some studies reported there are no significant differences among students in mathematics anxiety by gender. The result of this study showed that there is no statistically significant interaction effect between type of educational method and gender on the mathematics anxiety and mathematics achievement. Clearly, LS approach improved the ability of male and female students in problem solving and reduced their mathematics anxiety considerably, confirming previous studies [35], [38], [48]. 


\section{CONCLUSION}

In the Foundation Center, all lecturers teach using only one mathematics textbook and they are required to teach between 8 to 12 hours per week in each semester. Their working hours is from 8 am to $5 \mathrm{pm}$ Thus, they have ample opportunity to work collaboratively. Some of mathematics educators are not familiar with the problem solving method and Lesson Study (LS) is one of the best educational approaches in teaching mathematics that can help lecturers to have effective teaching. Therefore, they can improve the students' motivation, interest and abilities in problem solving and mathematics learning. When students improved their skills in problem solving, not only do they learn mathematics conceptually and experience the beauty of it but their mathematics anxiety would also be reduced.

\section{ACKNOWLEDGEMENTS}

We would like to show our gratitude to the director of the Foundation Center and lecturers for their support and cooperation. We also thank students who were a part of this study for their time and considerations during this research.

\section{REFERENCES}

[1] T. Tambychik and T. S. M. Meerah, "Students' difficulties in mathematics problem solving: What do they say?" Procedia Soc. Behav. Sci., vol. 8, pp. 142-151, 2010.

[2] G. Goldin, Perspectives on representation in mathematical learning and problem solving, 2nd ed. NY: Routledge, 2008.

[3] G. Ramirez, H. Chang, E. A. Maloney, S. C. Levine, and S. L. Beilock, "On the relationship between math anxiety and math achievement in early elementary school: The role of problem solving strategies," J. Exp. Child Psychol., vol. 141 , pp. 83-100, 2016

[4] C. C. Mon, M. H. Dali, and L. C. Sam, "Implementation of lesson study as an innovative professional development model among Malaysian school teachers," Malaysian J. Learn. Instr., vol. 13, no. 1, pp. 83-111, 2016.

[5] M. Khalid, "Fostering Problem Solving and Performance Assessment among Malaysian Mathematics Teachers," Sains Humanika, vol. 9, no. 1-2, pp. 51-55, 2017.

[6] Z. Ersozlu and M. Karakus, "Mathematics Anxiety: Mapping the Literature by Bibliometric Analysis," EURASIA J. Math. Sci. Technol. Educ., vol. 15, no. 2, pp. 1-12, 2019.

[7] B. Hemmings, P. Grootenbore, and R. Kay, "Predicting mathematics achievement: The influence of prior achievement and attitudes," Int. J. Sci. Math. Educ., vol. 9, no. 3, pp. 691-705, 2011.

[8] J. Hattie, "Visible learning - Synthesis of over 800 meta-analyses relating to achievement," J. Chem. Inf. Model., vol. 53, pp. 219-221, 2011.

[9] H. Patrick, P. Mantzicopoulos, A. Samarapungavan, and B. F. French, "Patterns of young children's motivation for science and teacher-child relationships," J. Exp. Educ., vol. 76, no. 2, pp. 121-144, 2008.

[10] M. Harsono, "The impact of lesson study on primary school teacher's knowledge and skills in differentiating primary school mathematics instruction: A digital mixed methods approach," Unpublished Doctoral Dissertation, Curtin University, Australia, 2016.

[11] H. I. Zanaton and M. R. Marziah, "Reflections on teaching and learning of mathematics through Lesson Study and Video Critique," Adv. Soc. Sci. Rsearch J., vol. 4, no. 1, pp. 50-61, 2017.

[12] L. Shulman, "Those who understand: knowledge growth in teaching," Educ. Res., vol. 15, no. 2, pp. 4-14, 1986.

[13] H. C. Hill and D. L. Ball, "The curious - and crucial - case of mathematical knowledge for teaching," Phi Delta Kappan, vol. 91, no. 2, pp. 68-71, 2009.

[14] L. Shulman, "Knowing and teaching: Foundations of the new reform," Harv. Educ. Rev., vol. 57, no. 1, pp. 1-22, 1987.

[15] J. Baumert, et al., "Teachers' Mathematical Knowledge, Cognitive Activation in Classroom, and Student Progress," Am. Educ. Res. J., vol. 47, no. 1, pp. 133-180, 2010.

[16] S. Norton, "The relationship between mathematical content knowledge and mathematical pedagogical content knowledge of prospective primary teachers," J. Math. Teach. Educ., vol. 22, pp. 1-26, 2019.

[17] Y. M. Yusof and E. Zakaria, "The Integration of Teacher's Pedagogical Content Knowledge Components in Teaching Linear Equation," Int. Educ. Stud., vol. 8, no. 11, pp. 26-33, 2015.

[18] C. Xenofontos and P. Andrews, "Defining mathematical problems and problem solving: prospective primary teachers' beliefs in Cyprus and England," Math. Educ. Res. J., vol. 26, no. 2, pp. 279-299, 2014.

[19] D. Brijlall, "Exploring The Stages of Polya's Problem-solving Model during Collaborative Learning: A Case of Fractions," Int. J. Educ. Sci., vol. 11, no. 3, pp. 291-299, 2015.

[20] E. Ghasemi and H. Burley, "Gender, affect, and math: a cross-national meta-analysis of Trends in International Mathematics and Science Study 2015 outcomes," Large-scale Assessments Educ., vol. 7, no. 10, pp. 1-25, 2019.

[21] D. Reilly, D. L. Neumann, and G. Andrews, "Investigating gender differences in mathematics and science: Results from the 2011 Trends in Mathematics and Science Survey," Res. Sci. Educ., vol. 49, pp. 25-50, 2019.

[22] M. Samuelsson and J. Samuelsson, "Gender differences in boys' and girls' perception of teaching and learning mathematics," Open Rev. Educ. Res., vol. 3, no. 1, pp. 18-34, 2016. 
[23] I. V. S. Mullis, M. O. Martin, and P. Foy, TIMSS 2015 International Results in Mathematics. Chestnut Hill, MA: TIMSS \& PIRLS International Study Center, Boston College, 2016.

[24] S. M. Lindberg, J. S. Hyde, J. L. Petersen, and M. C. Linn, "New Trends in Gender and Mathematics Performance: A Meta-Analysis," Psychol. Bull., vol. 136, no. 6, pp. 1123-1135, 2010.

[25] B. A. Nosek and F. L. Smyth, "Implicit Social Cognitions Predict Sex Differences in Math Engagement and Achievement," Am. Educ. Res. J., vol. 48, no. 5, pp. 1125-1156, 2011.

[26] F. Kazemi, A. Zaman, and A. Ghafar, "Localizing Lesson Study for the Math Teachers' Professional Development, Necessities and Prohibitions," J. Appl. Environ. Biol. Sci., vol. 4, no. 9S, pp. 504-508, 2014.

[27] B. Doig and S. Groves, "Japanese Lesson Study: Teacher Professional Development through Communities of Inquiry," Math. Teach. Educ. Dev., vol. 13, no. 1, pp. 77-93, 2011.

[28] T. Abiko, "A response from Japan to LRP's ten principles for effective pedagogy," Res. Pap. Educ., vol. 26, no. 3, pp. 357-365, 2011.

[29] K. Matanluk, K. Johari, and O. Matanluk, "The Perception of Teachers and Students toward Lesson Study Implementation at Rural School of Sabah: A Pilot Study,” Procedia - Soc. Behav. Sci., vol. 90, pp. 245-250, 2013.

[30] T. Bergqvist, "Problem solving in mathematics education : learning problem solving and learning through problem solving," Proc. from 13th ProMath Conf., Umeå, UMERC, 2011, pp. 5-16.

[31] A. Takahashi and T. McDougal, "Collaborative lesson research: maximizing the impact of lesson study," ZDM Math. Educ., vol. 48, pp. 513-526, 2016.

[32] T. Fujii, "Designing and adapting tasks in lesson planning: a critical process of Lesson Study," ZDM - Math. Educ., vol. 48, no. 4, pp. 411-423, 2016.

[33] M. Yoshida, "A case study of a Japanese approach to improving instruction through school-based teacher development," Ph.D Thesis, University of Chicago, 1999.

[34] T. Fujii, "Theorizing Lesson Study in mathematics education as an emerging research area: Identifying components and its structure of Lesson Study," Proc. Second Annu. spring Conf. Japan Soc. Math. Educ., 2014, pp. 111-118.

[35] S. H. Mohamed and R. A. Tarmizi, "Anxiety in mathematics learning among secondary school learners: A comparative study between Tanzania and Malaysia," Procedia - Soc. Behav. Sci., vol. 8, pp. 498-504, 2010.

[36] F. C. Richardson and R. M. Suinn, "The mathematics anxiety rating scale: Psychometric data," J. Couns. Psychol., vol. 19, no. 6, pp. 551-554, 1972.

[37] D. Park, G. Ramirez, and S. L. Beilock, “The role of expressive writing in math anxiety," J. Exp. Psychol. Appl., vol. 20, no. 2, pp. 103-111, 2014.

[38] E. Zakaria, N. M. Zain, N. A. Ahmad, and A. Erlina, "Mathematics anxiety and achievement among secondary school students," Am. J. Appl. Sci., vol. 9, no. 11, pp. 1828-1832, 2012.

[39] G. Gresham, "A study of mathematics anxiety in pre-service teachers," Early Child. Educ. J., vol. 32, no. 5, pp. 181-188, 2007.

[40] A. E. Foley, J. B. Herts, F. Borgonovi, S. Guerriero, S. C. Levine, and S. L. Beilock, "The Math AnxietyPerformance Link: A Global Phenomenon," Curr. Dir. Psychol. Sci., vol. 26, no. 1, pp. 52-58, 2017.

[41] B. Sherman and D. Wither, "Mathematics Anxiety and Mathematics Achievement," Math. Educ. Res. J., vol. 15, no. 2, pp. 138-150, 2003.

[42] P. Vitasari, M. N. A. Wahab, A. Othman, T. Herawan, and S. K. Sinnadurai, "The relationship between study anxiety and academic performance among engineering students," Procedia - Soc. Behav. Sci., vol. 8, no. 5, pp. 490-497, 2010.

[43] M. Erden and S. Akgül, "Predictive Power of Math Anxiety and Perceived Social Support From Teacher for Primary Students' Mathematics Achievement," J. Theory Pract. Educ. Artic., vol. 6, no. 1, pp. 3-16, 2010.

[44] K. O'Leary, C. L. Fitzpatrick, and D. Hallett, "Math anxiety is related to some, but not all, experiences with math," Front. Psychol., vol. 8, pp. 1-14, 2017.

[45] L. Kvedere, "Mathematics Self-concept of the 9th Grade Students in Latvia," Procedia - Soc. Behav. Sci., vol. 46, pp. 3380-3384, 2012.

[46] A. Dowker, A. Sarkar, and C. Y. Looi, "Mathematics anxiety: What have we learned in 60 years?" Front. Psychol., vol. 7, no. 508, pp. 1-16, 2016.

[47] A. Devine, K. Fawcett, D. Szucs, and A. Dowker, "Gender differences in mathematics anxiety and the relation to mathematics performance while controlling for test anxiety," Behav. Brain Funct., vol. 8, no. 33, pp. 1-9, 2012.

[48] M. Kyttälä and P. M. Björn, "The role of literacy skills in adolescents' mathematics word problem performance: Controlling for visuo-spatial ability and mathematics anxiety," Learn. Individ. Differ., vol. 29, pp. 59-66, 2014.

[49] M. Ali Al Mutawah, "The Influence of Mathematics Anxiety in Middle and High School Students Math Achievement," Int. Educ. Stud., vol. 8, no. 11, pp. 239-252, 2015.

[50] E. Carey, F. Hill, A. Devine, and D. Szucs, "The Chicken or the Egg? The Direction of the Relationship Between Mathematics Anxiety and Mathematics Performance," Front. Psychol., vol. 6, pp. 1-6, 2016.

[51] N. E. Betz, "Prevalence, distribution, and correlates of math anxiety in college students," J. Couns. Psychol., vol. 25, no. 5, pp. 441-448, 1978.

[52] H. Bai, "Cross-validating a bidimensional mathematics anxiety scale," Assessment, vol. 18, no. 1, pp. 115-122, 2011. 